\title{
Animating Archaeology: Local Theories and Conceptually Open-ended Methodologies
}

\author{
Benjamin Alberti \& Yvonne Marshall
}

\begin{abstract}
Animists' theories of matter must be given equivalence at the level of theory if we are to understand adequately the nature of ontological difference in the past. The current model is of a natural ontological continuum that connects all cultures, grounding our culturally relativist worldviews in a common world. Indigenous peoples' worlds are thought of as fascinating but ultimately mistaken ways of knowing the world. We demonstrate how ontologically oriented theorists Eduardo Viveiros de Castro, Karen Barad and Tim Ingold in conjuncture with an anti-representationalist methodology can provide the necessary conditions for alternative ontologies to emerge in archaeology. Anthropo-zoomorphic 'body-pots' from first-millennium AD northwest Argentina anticipate the possibility that matter was conceptualized as chronically unstable, inherently undifferentiated, and ultimately practice-dependent.
\end{abstract}

Here we have a peculiar ontology which we could define (as a) para-ontology, an ontology which is yet to be thought.

Giorgio Agamben, 'What is a paradigm?'

\section{Introduction: from culture to ontology}

It is apparent that accounts of 'non-modern' worlds often insist on wholly other ways of being and of conceptualizing reality. As archaeologists, then, how do we access and write about worlds that could 'be' entirely incommensurable with our own world of experience? What theoretical and methodological tools are necessary for the task? Even to speak of multiple ontologies can seem oxymoronic. 'Ontology' is supposed to carry the weight of the real world, to be the ground of action and understanding for archaeology as for other social and natural disciplines; and so to pluralize it sounds like a trivialization, or a 'postmodern' discursive trick. Conversely, the plural risks the suggestion of synonymy with 'culture'. Both of these very real possibilities are symptoms of precisely the elision of ontological concerns by epistemological ones engendered by modernity (Henare et al. 2007; Latour 1993; Rollason 2008; Viveiros de Castro 2003).
We use 'ontology', here, to mean the possibility of giving credence to other worlds, not simply as a noble relativizing but ultimately hypocritical gesture but as a means to force the production of new material concepts. We argue that 'ontological breakthrough' (Henare et al. 2007) in archaeology is possible if indigenous theories are taken seriously as ontologies rather than epistemologies and combined with insights from Western theories of materiality that reveal matter as ontologically relational and inherently indeterminate. Animism, then, is not a resource for theory but a source of theory.

Archaeological references to ethnographies serve to enhance or measure the accuracy of our interpretations, and have proven a productive source of analogies for past life and as illustrative material for theoretical debate, especially around the notion of 'object agency' (e.g. Gell 1998; see Brown \& Walker 2008). The philosophical underpinnings of animist beliefs and practices are rarely treated as theory in their own right, but rather as mistaken epistemologies. In contrast, Eduardo Viveiros de Castro (2006, 16) has argued that to avoid such 'epistemological pick pocketing' we must treat non-Western theories in a 'symmetrical' way to western theories (sensu

Cambridge Archaeological Journal 19:3, 344-56 @ 2009 McDonald Institute for Archaeological Research doi:10.1017/S0959774309000535 Received 1 April 2009; Accepted 20 May 2009; Revised 30 July 2009 


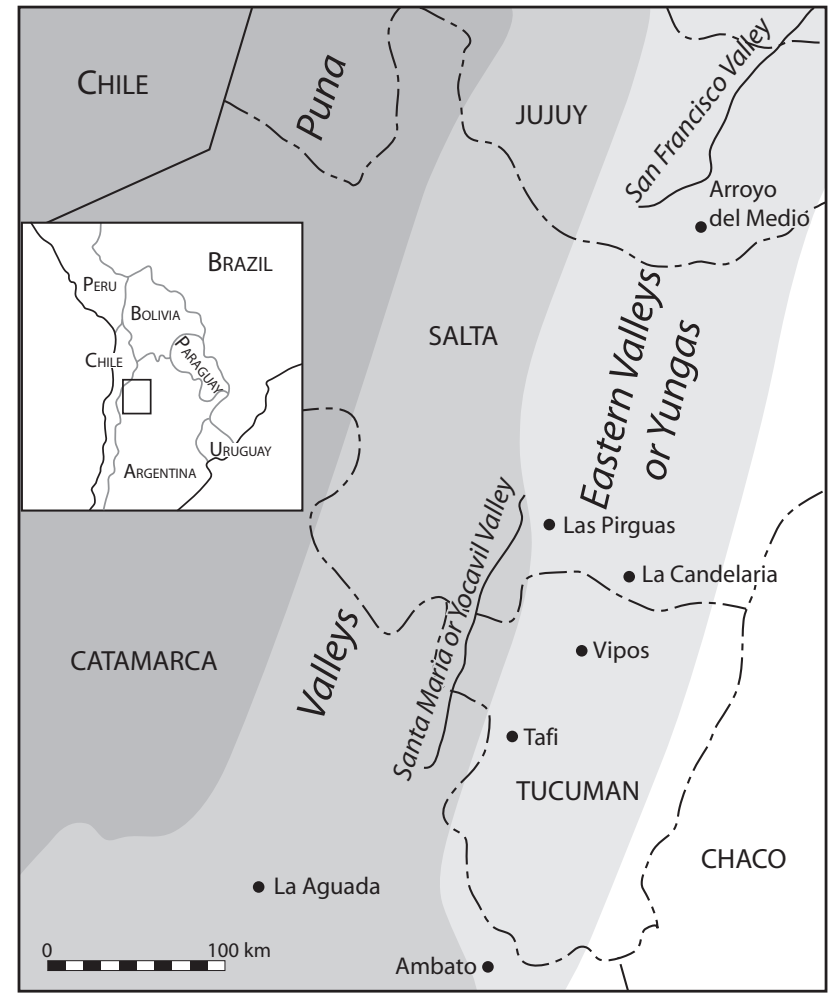

Figure 1. Map of northwest Argentina showing extension of La Candelaria and San Francisco cultural material around the Eastern Valleys or Yungas.

Latour 1993). Similarly, anthropologist Tim Ingold, and feminist philosopher and physicist Karen Barad, both introduce us to 'relational ontology' as a more fundamental account of the inherent dynamism and mattering of the world than conventional Western conceptualization allows. We nonetheless suggest that the globalizing tendency of both theorists is problematic. We need to challenge this tendency by refusing to grant priority to any particular theoretical position and by adopting methodologies that are responsive to alternative ontologies. A methodology grounded in the potential for alternative worlds to become manifest in archaeological material is adapted from Henare et al.'s (2007) call to 'take seriously' apparently anomalous claims in ethnography about the congruence of meaning and thing.

In this article we explore the theoretical possibilities of an archaeology which takes ontological alterity seriously. We begin by discussing some of the key commonalities and differences in arguments for new kinds of ontology put forward by Viveiros de Castro, Tim Ingold and Karen Barad. We then consider how their ideas might enable new ways of thinking biomorphic vessels from first-millennium AD northwest Argentina (Figs. 1-4). What emerges is the possibility that the local ontology was one in which a background of 'indifference' in bodies and matter provoked differentiation through the materialization of specific bodies and 'body-pots'. Once materialized, however, bodies and body-pots required constant management to maintain their specificity in the face of a general instability of matter. 'Agency' is then an effect of the relations that produce the differentiation and stabilization of specific material forms, not their cause.

\section{Archaeology, animism, and 'object agency'}

Traditionally defined as a generalized belief in an 'animating' spirit or soul (Tylor 1993 (1871)), the resurgence of interest in animism has included its reformulation as a type of relational ontology (e.g. Descola 1996; Ingold 2000; Alberti \& Bray, this issue). Ethnographic accounts of other peoples' worlds are simultaneously the main provocation and the chief resource to think about ontological alterity through archaeology. The nature of their inclusion has been crucial in setting limits to what can be said, and parallels the type of credibility afforded such ostensible 'beliefs' (see Alberti \& Bray, this issue). Animism has been incorporated both as a source for models of past life, an analogical usage, and a resource for archaeological theory. The notion of 'object agency' illustrates how productive such incorporation has been and its confluence with contemporary materiality theory. Also revealed, however, is a potential barrier to understanding the world as quite literally 'other', as the notion itself relies on a 'leap of faith'.

The incorporation of a focus on animism in archaeology has paralleled an interest in exploring ethnographic analogies that challenge taken-forgranted concepts, such as personhood (e.g. Fowler 2004), gender and sexuality (e.g. Weismantel 2004), and materiality (e.g. Parker Pearson et al. 2006). This ethnographically rich work has been enormously productive of theories and analogies for archaeological consumption - i.e. as 'fuel' or 'leverage' for understanding past lives (Fowler 2004; Thomas 2004, 241). Broadly we agree with Thomas $(2004,241)$ when he argues that 'the most important role of ethnographic analogy lies not in filling in the gaps in our knowledge of prehistoric societies but in troubling and disrupting what we think we already know'. Nonetheless, models based on the identification of material correlates and the application of analogies are likely to recover variations of particular epistemologies (worldviews), rather than ontologies (worlds) precisely because of the tendency to reduce others' ontologies to epistemolo- 
gies in the present. In other words, epistemological concerns posit culture or belief as a lens through which we 'know' a singular the world, whereas ontology is concerned with what it is we consider 'the world' to be. The difference is one between 'how we know' and 'what there is' - we tend to assume that the latter is a universal given and the former culturally variable. As such, analogies will likely remain fascinating epistemological alternatives to a Western worldview (what we 'know'), rather than alternative ontologies (what is real to us), if a uni-natural model remains dominant in archaeology (see Viveiros de Castro 1998; 2003). Despite the value of agentive notions of matter and things, we argue that 'object agency' exposes a lack of commitment to other peoples' worlds and theories, acting as a cognitive trap that prevents archaeologists from launching a fully ontological inquiry. The issue is what status archaeologists afford others' claims and how we allow such notions to infiltrate or affect our theories.

Recent theories of materiality in archaeology, especially in relation to the notion of object agency, clearly converge with ethnographic accounts of other peoples' relations to their environment and locally-defined notions of agency (e.g. Connoller 2004; Ingold 2000; Sillar 2004). A stress on the active role of material culture (Hodder 1986) has evolved into thinking of objects or material as agents (e.g. Knappett \& Malafouris 2008). Fairly widely accepted, the idea is conceptually uncomplicated - things do, after all, make us do things. When referring to the potential agency of materials or objects, the notion of 'secondary agency', popularized by Gell (1998), helped convince people of the analytical legitimacy of such non-human agents. The term implies a distinction between 'human agency' and a kind of 'object agency' as its derivative (e.g. Robb 2005). In particular circumstances certain things can act as stand-ins for agents through a process of abduction. Some objects clearly do have natural properties that mean they quite literally can 'act on' people (for example trees fall) and people act as if objects could act (for example Alfred Gell and his Toyota car). In the latter case, it is seen to be unimportant whether such beliefs are true; what is significant is that people act towards things as if they had agency. Non-Western peoples' beliefs in animacy were a key inspiration for Gell (1998) and continue to impact archaeology through his work. As Brown \& Emery $(2008,302)$ contend, activity between human and non-human agents can be revealed once the modern dichotomy 'that splits the world into people and things' has been suspended and we 'seriously accept that some of what we recover in the archaeological record reflects daily interactions between human and important nonhuman agents'.

Even though the potential for archaeological interpretation and theory building on the basis of analogies with animist practices is clear, they are fundamentally limited when it comes to uncovering past ontologies because the 'leap of faith' required to understand ontological difference is ultimately not taken. At root is a confusion of ontological with epistemological claims. As Viveiros de Castro (2003) has noted, other peoples' ontological commitments (their worlds) have been converted by anthropology into epistemologies (worldviews). As such, the incommensurability of other peoples' worlds with ours can only ever be understood at the level of 'cultural' difference; their ontologies can only be more-or-less mistaken, fragmentary and partial 'representations' of our singular 'ontology', synonymous with 'nature'. Consequently, what we see in the use of interpretive ethnographic analogies and notions such as 'object agency' is a greater acceptance of epistemological diversity, but not necessarily a means to access other ontologies. In fact, the notion of 'object agency', especially in its 'secondary agency' form, relies on the researcher's conversion of an ontological claim into an epistemological one, allowing us to adopt a relativist stance in relation to others' beliefs about the world without actually subscribing to such beliefs (a form of 'hypocrisy': Viveiros de Castro 2002, 132-3). Thus, our apparent commitment to their beliefs masks the absence of our belief in their actual commitments.

\section{Procedural equivalence in theory}

The potential for archaeology to uncover ontological alterity partly lies in sidestepping the elision of ontological claims by epistemological ones and realizing the potential in others' theories of the world. Viveiros de Castro $(2002,115 ; 2003)$ has explored what happens when 'the native's discourse functions within the anthropologist's discourse in such a way (that) it produces a reciprocal "knowledge-effect" on the latter'. He asks:

(W)hat happens when we take native thought seriously? When the anthropologist's aim ceases to be to explain, interpret, contextualize and rationalize this thought, and becomes one of using it, drawing out its consequences, and ascertaining the effects it may produce on our own? (Viveiros de Castro 2003, 11)

In apparent agreement, Ingold $(2006,19)$ argues we should 'reanimate' Western thought on the basis of rethinking indigenous animism. A subtle difference is that while Ingold (e.g. 2006, 19) offers a corrective 
to our misconceptions of how the world 'really is' on the basis of animists' accounts, Viveiros de Castro (e.g. 2004a) rehabilitates indigenous thought as an intellectual resource for problematizing Western categories of thought and the notion of 'a world as it really is', whether relational or otherwise. Neither is the answer to privilege other peoples' accounts of the world, as in nativism (which is not Ingold's project), but rather to engage other peoples' ontological or conceptual work as 'procedurally equivalent' to what we do as anthropologists; properly speaking, their theories are anthropologies too (Viveiros de Castro 2003; 2004a, 4; 2006, 16).

The taking seriously of native thought, then, means that instead of neutralizing it through the application of universal concepts, it is treated as philosophically challenging, a potential equivalent to western philosophical doctrines (Viveiros de Castro 2003). Viveiros de Castro (e.g. 1998; 2004a,b) applies his argument that Amazonian thought as thought should impact anthropology and 'humanity' by thinking through the implications of 'perspectivist' theory. He uses the label 'perspectivism' to designate a 'type of cosmology' common to Amazonian groups, but also to intervene in the relativism/universalism antinomy through a consideration of the nature/culture question as it manifests itself in Amazonian thought (2003, 5-6; $2006,14)$. Instead, therefore, of the notion of a unitary nature and many cultures each with its own cultural perspective on that nature (i.e. multiculturalism), perspectivism relies on the notion of 'transpecific personhood' in which 'souls' (human and non-human) share a common origin and unity, while bodies and affects are the seat of difference (Castro de Viveiros 1998; 2004a, 3, 6). One's world (nature) is dependent on the body that one occupies. However, one shares concepts with other 'souls'; therefore, how one sees the world will remain the same across species. Instead of multiculturalism and uninaturalism (the dominant Western model), one gets uniculturalism and multinaturalism: a unitary or constant epistemology and variable or plural ontologies.

Perspectivism entails a rethinking of the nature of relations. In a reconceptualization of anthropology's fundamental task of comparison, or translation, Viveiros de Castro $(2004 a, 18)$ shows that to talk of being related in the West implies having something in common; perspectival relationality, in contrast, is founded on 'difference rather than sameness'. The distinction between the two modes of relation is revealed in the use of 'brother' as the common idiom of relatedness in the west versus 'brother-in-law' or 'cross cousin' in Amazonia. The first mode implies unity through a common relation to a third term; in the second mode the relation is one of diametric opposition, i.e. 'the terms are linked by that which separates them' (Strathern 1992, as cited in Viveiros de Castro 2004a, 19). The difference emerges once we consider that the underlying premise of perspectivism is a background of commonality, trans-specific 'cultural unity'. Establishing a relation is then to 'differentiate indifference', to 'insert a difference where indifference was implied' (Viveiros de Castro 2004a, 18-19). By contrast, in the West 'to relate is to assimilate, to unify, and to identify', producing analyses that posit a continuity on the basis of a shared ontology ('nature'). In the perspectivist model, to relate is to differ: 'translation (is) an operation of differentiation - a production of difference - that connects the two discourses to the precise extent to which they are not saying the same thing' about synonymic concepts. For anthropology, the danger of the Western mode lies in imagining an 'overly simplified' relation between it and its object, resulting from 'a desire for ontological monism', that is, relations of identity such as that imagined by social construction - the distinction between a 'real' world of brute facts and 'human world' of institutional ones (Viveiros de Castro 2004a, 16, 20).

\section{A world in flux: matter's inherent dynamism}

To assume we need to know exactly the metaphysical underpinnings of alternative ontological possibilities seems to suggest we need to re-ground other peoples' theories in the 'truths' of our natural sciences. That is not our intention. Rather, understanding the fundamentally relational ontology of the physical world in terms of our own, scientific theories further prepares the ground for imagining the possibility that other peoples' worlds are as they say they are. In other words, pluralizing 'ontologies' may not be enough to break a habit of mind that refuses to grant a literal rather than metaphorical presence to indigenous peoples' worlds or the past.

The physical world as objective fact has been taken as the ground of reality since at least the advent of modernity (Latour 1993; Viveiros de Castro 1998; 2003; see Thomas 2004). The remit of science has been to reveal the immutable yet hidden truths of nature. Tim Ingold (2000; 2006; 2007a,b) and Karen Barad $(2003 ; 2007)$, as two different disciplinary versions of a 'Western theoretical animism', challenge the Cartesian assumption of an a priori separation of the world into two ontological domains: matter and meaning (Barad 2007), the physical world and the world of ideas (Ingold 2007a, 3). Their solution is to re-invigorate matter and re-materialize meaning through practice. 
Barad's use of matter as an ontological category and Ingold's focus on materials as opposed to matter share a concern with the dynamic, ultimately relationally constituted, and inherently indeterminate state of 'nature'. According to Barad (2007, 151 emphasis in original), 'matter is substance in its intra-active becoming - not a thing but a doing, a congealing of agency'.

To demonstrate how the generalized ontological indeterminacy is resolved into local determinacy, Barad (2007, 81-3, 99-106) develops the example of the 'wave-particle duality paradox' of quantum physics in which matter is shown to act as both a wave or a particle, yet these are mutually exclusive states. In Barad's reading, there is no paradox: the entirety of the material conditions necessary to conduct the experiment produces the specific state of the object measured (in this case, an electron). A wave or particle is produced within the specific 'phenomenon' that includes both apparatus and object. In other words, there are no independent, individual 'things' (objects, subjects, etc.) with pre-determined properties or identities, only 'things-in-phenomena'. The concepts 'wave' and 'particle' are not properties intrinsic to the electron, but are quite literally embodied by the larger 'apparatus', so that each concept is material only in a very specific sense. The specific material conditions of an apparatus determine the boundaries and properties of the measured object as well as the measuring apparatus.

For Ingold, the relational constitution of being consists of 'a field' of 'interwoven lines' - or a 'meshwork' - in contrast to interconnected points, or a set of pre-determined objects (Ingold 2006, 13). The relation 'is a line along which materials flow, mix and mutate' (Ingold 2007b, 35). According to Ingold $(2007 b, 35)$, 'every thing' is itself an entanglement of relations, including both persons and things, which are not 'nodes' or something qualitatively different from the relations themselves, but rather 'bundles of relations'. The environment itself, as a 'domain of entanglement', consists of the interwoven growth of many such relational beings.

Similarly, for Barad, relational 'phenomena' and not objects are ontologically primitive and therefore constitutive of physical reality (Barad 2007, 140, 151). Things exist only in relation to other things. In contrast to a substance ontology, subjects and objects with determinate boundaries and properties are outcomes of relationships and do not precede them. An important consequence is that what we call the 'objective referent' to which we can properly attribute properties, predicates, attributes, and so on, are not objects and subjects but rather the phenomenon as a whole (i.e. both object and apparatus). Ingold also insists that things or materials do not have pre-occurent properties but are 'processual and relational'; properties are histories rather than attributes, as illustrated in his point about the properties of stone as opposed to the notion of the 'materiality' of stone:

Stoniness, then, is not in the stone's 'nature', in its materiality. Nor is it merely in the mind of the observer or practitioner. Rather, it emerges through the stone's involvement in its total surroundingsincluding you, the observer-and from the manifold ways in which it is engaged in the currents of the lifeworld. (Ingold 2007a, 15)

Just as 'electrons' do not bring with them properties that pre-exist the phenomenon in which they are manifested or measured, the properties of stone are not internal to it as 'stoniness'. Properly speaking, the properties of stone are properties of the larger phenomenon of which the stone and observer are constitutive parts.

If things were to stop their 'action' of relating they would no longer be. If relations are ontologically prior, then the world is inherently animated and dynamic. In Ingold's account, life is continually in a process of generation, of re-birth; agency is synonymous with life, while for Barad, agency is an effect of ongoing 'intra-actions', the causal structure that differentiates 'thing-in-phenomena'. In contrast to the notion of 'object agency', then, agency is not separated into two different types - intentional and effective. Their notion of agency is quite different from simply refusing humans sole propriety over agency, as the democratizing notions of 'secondary agent' (Gell 1998) and 'actant' (Latour 1993) imply. As Sillar (this issue) argues, agency is the effect of relations (see also Gardner 2008; Gell 1998; Joyce \& Lopiparo 2005; Robb 2008), but in Barad's and Ingold's accounts, those relations are not between pre-existing entities, but are the outcome of the differentiating impulse that produces determinate entities in the first place. As such, agency is less a choice between external natural causes and human-authored intentional action, and more an effect of ongoing material-discursive practices that produce both human and non-human in the first place.

Both Barad and Ingold propose 'meta-ontologies', quite different from traditional substance ontologies yet with the same implied claim to universality. Barad's ontology provides a generalized explanation for the mechanism of ontological constitution and reconfiguration, which is both physical and meaningful, but which is radically open to reconfiguration and pluralization. Ethnography is central to Ingold's world, but it is still a singular world. We are left with 
the problem of the relationship between these global, and implicitly singular theories and ontologies, and the status of other peoples' ontological claims. A similar point could be made about the 'meta-ontology' under-girding 'symmetrical' approaches in archaeology (e.g. Olsen 2003; Witmore 2007; see also Henare et al. 2007, 7). To propose a relational ontology based on matter's inherent dynamism solves the problem of needing an animating human hand to enable agency and action, but it does not necessarily place us on a path to ontological alterity (multiple worlds) such as the Amazonian ontologies discussed by Viveiros de Castro. This requires a further step which depends upon taking seriously the 'cross reality' challenges which emerge from anthropological and archaeological accounts of other worlds.

\section{Open-ended conceptuality}

In a discussion of the methodological implications of new theories of 'agency' in archaeology, Dobres \& Robb (2005) argued that theory, method, and methodology need to be thought and practised together rather than sequentially. Drawing on Viveiros de Castro's theories, Henare et al. (2007) propose a methodology for anthropology that gets at ontological alterity. In line with Dobres \& Robb (2005), they argue that theory production must be ongoing rather than pre-determined. Present analytic approaches are problematic, they argue, because they rely on a 'classificatory repertoire intended for refinement and expansion' (Henare et al. 2007, 5) and thus disallow the possibility of 'ontological breakthrough' because data are fitted into pre-existing schemas. In contrast, they develop a heuristic concept of the 'thing', which is treated as a more-or-less empty signifier (much like Strathern's (1988) 'person'); the things themselves as they are encountered act as 'conduits for concept production' (Henare et al. 2007, 7). New analytical frameworks and theory are produced as a result of the encounter, not prior to it.

This methodological minimalism opens up analyses, enabling apparent anomalies to provide a route into ontological alterity (see Bray, this issue). Conventionally, anomalous things are treated as epistemological conundrums, the solutions to which are thought to lie in expanding familiar interpretive categories to encompass them (Henare et al. 2007, 6; e.g. Holbraad 2007 on the history of mana interpretations). To get around the conventional separation of a thing and its meaning, Henare et al. (2007, 2-3) adopt the anti-representationalist strategy of 'radical essentialism' by 'taking things in the field as they present themselves, rather than immediately assuming that they signify, represent, or stand for something else'. Holbraad's (2007) work among the Ifá diviners of Cuba reveals the powder-power, aché, as neither an isolatable concept nor thing. Approached by an Ifá diviner who thinks powder is power and vice versa, we need not assume that our representations are inadequate; nor need we try to explain why someone (or some 'culture') might think powder were power. Holbraad (2007) shows that refusing a priori the separation between thing and concept enables him to 'think through' a new concept (powder-power) and explain Ifá ontology as constituted by motility and transcendence. In another example, Marshall (2008) examines the confusion experienced by European explorers and traders attempting to distinguish persons of high rank among the Nuu-chah-Nulth people of the North American Northwest Coast despite their almost complete disregard for status-specific dress or insignia. The only example described was a rain hat depicting whaling scenes presumed to mark out a chief. But even the rain hats did not, in fact could not, 'signify' rank or status because persons were not stabilized and marked out as particular kinds of being, or understood to have fixed identities. Instead people needed to maintain themselves in a state of constant motion, shifting and transforming between positions and states. In this process material objects were taken up to enable such movement, not to designate, display or hold steady an achieved position. Little wonder the European newcomers were perplexed.

Refusing the separation of concept and thing is not confined to anthropology or archaeology. It is happening within the physical sciences too. The revelatory potential of anomalies also drives Barad's (2007) work (for example, the 'wave-particle duality paradox'). If within the terms of their own theories the hard sciences are able to encompass the possibility that physical reality itself, as conceived by Western science, is fundamentally relational, then concept production directed at archaeological material must also encompass the virtualities of its physicality. Specifically, matter as dynamic and continuously open to reconfiguration and agency-as-effect or 'in life' are allied notions with heuristic potential. Archaeologists and anthropologists have different opportunities for recognizing and uncovering anomalies. Holbraad's and Viveiros de Castro's anthropological accounts have an underdeveloped sense of the 'matter' of the thing. In contrast, because of the irreducibly material nature of archaeological 'concept-things', their 'prosaic' character (Holbraad 2007,208 ) will necessarily have greater weight in the investigation and rethinking of concepts. 


\section{Towards 'ontological breakthrough' in first- millennium AD northwest Argentina}

Research currently being conducted by Alberti on materials from northwest Argentina, particularly biomorphic pots, is the grounds for elaboration of the terms in which ontological difference can become intelligible (Alberti 2006; 2007; Figs. 1-4). This is not a case study or example, which would entail actually understanding the logic of the ontology of the pots, but rather an extension of the theoretical discussion. A contrast is drawn between two possible approaches to the Argentinian material in order to illuminate the difference between a conventional interpretation, which rests on questions of an epistemological nature, and an approach which attempts to take ontological alterity seriously. The first, more traditional approach would be to treat the pots as 'representations' of an animist (or perspectivist) worldview. Here, analogies with ethnographic parallels are useful. The second approach, and the one advocated here for getting at ontological difference, is that 'worldviews' is not what we are after at all but precisely 'worlds', in which case perspectivism as a set of theoretical possibilities must be adopted in order to understand the pots.

The anthropo-zoomorphic vessels and burial material from the La Candelaria and San Francisco region of northwest Argentina during the first millennium AD reveal exaggerated anatomical features, human/bird or human/animal 'hybrid' forms, and biomorphic protrusions or 'mamelones' (Figs. 2-3; Alberti 2007; Goretti 2006). There are also exceptional pieces of finer quality that depict single or twined animals in a naturalistic style. Much of the material was recovered by collectors, so contextual data are sparse. Poorly preserved settlements with small assemblages of urn burials in proximity predominate; the material recovered archaeologically largely comes from such burials (Baldini et al. 2003; Heredia 1968; 1975). While the material shares characteristics with a tradition that encompasses many of the cultures of the wider area, no canon for the imagery has been developed (Alberti 2007; DeMarrais 2007; Lazzari 2005).

When faced with this body of material the immediate question is what does it mean? A conventional answer is that it represents the beliefs of past peoples. The task of archaeologists is then to re-construct more-or-less accurate interpretations of the underlying meanings inherent in the vessel forms and their imagery. Since the pots and their imagery fit within a generally Andean framework of beliefs, they are taken to indicate or to have been involved in ritual and other activities (e.g. DeMarrais 2007; González

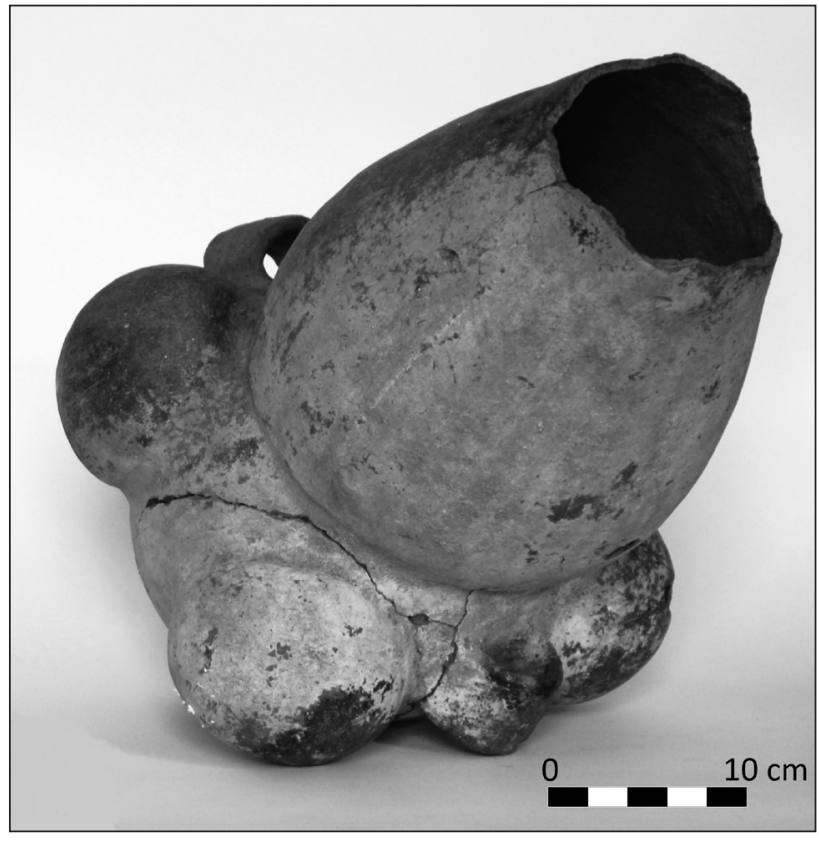

Figure 2. La Candelaria-style ceramic vessel showing biomorphic 'protrusions'. (Museo de La Universidad Nacional de Tucumán; photograph, B. Alberti.)

1977; Llamazares \& Sarasola 2006). Thus, here a focus on animism would entail 'reading off' such meanings from the pots, perhaps on the basis of analogy with ethnohistoric or ethnographic accounts. As such, in an earlier publication Alberti (2007) made the case that the location of the La Candelaria and San Francisco cultures, wedged, as it seemed to him, between the Andes and the lowlands, enabled him to read off from his material Amazonian cosmological content, an analogical usage.

Following representationalist logic, analogical correspondence could be sought between the form of the vessels and the content of Amazonian myth. The La Candelaria material corresponds well with some elements of Amazonian cosmology. The hybrid pot forms (e.g. Fig. 3) recall the widespread Amazonian belief in a transition point from mythic time when humans and animals were not yet clearly distinguished to current-day discrete identities (Lévi-Strauss 1969). Alternatively, the hybrid figures could be taken to represent shamanic journeys, where distinct points of view were achieved by hallucinogen-induced corporeal transformation (e.g. Llamazares \& Sarasola 2006; Pérez Gollán 2000). More adventurously, the biomorphic protrusions and general unsettledness of form could indicate the existence of 'the mythical riverrun of fluent metamorphosis' that continues its 


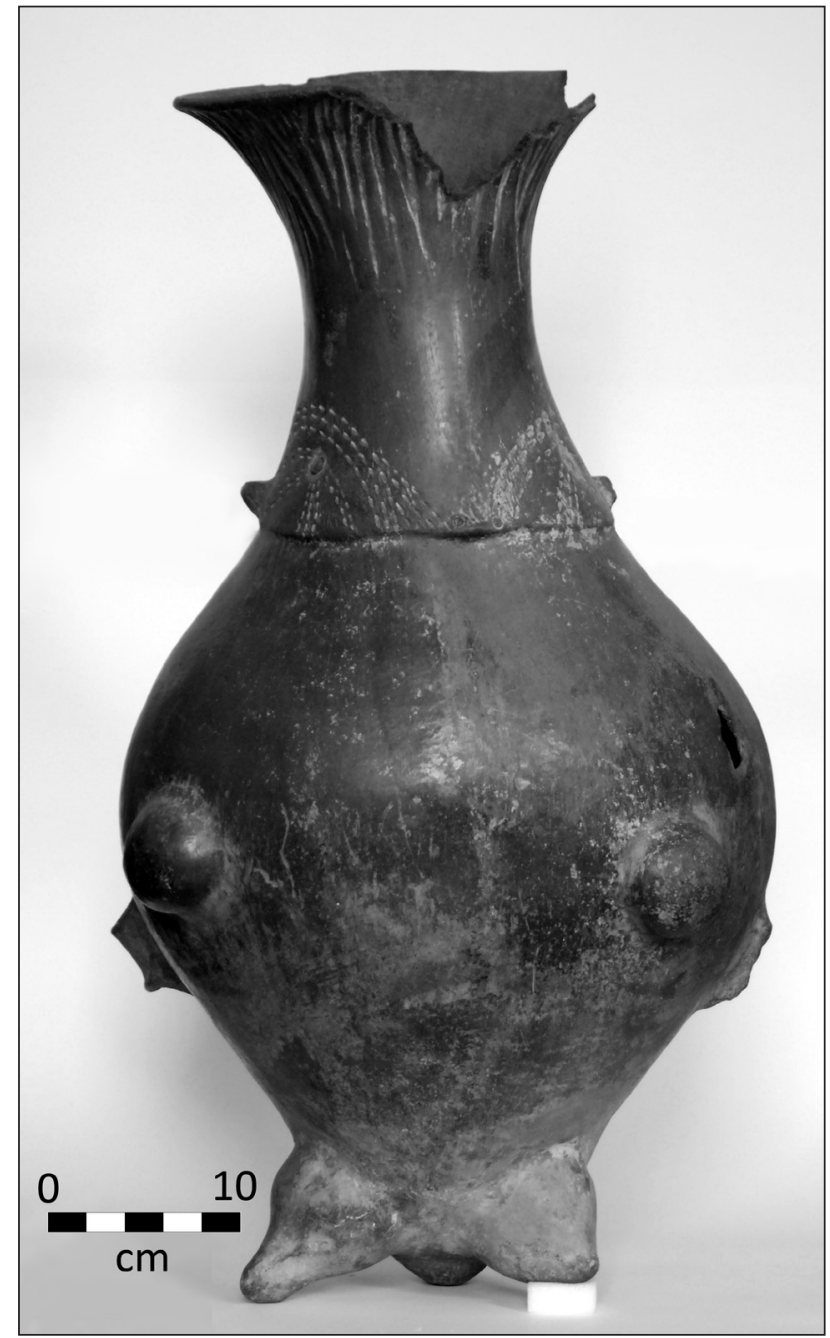

Figure 3. La Candelaria-style zoomorphic ceramic vessel. (Museo de La Universidad Nacional de Tucumán; photograph, B. Alberti.)

'turbulent course' below the separate surface of the bodies that separate species (e.g. Figs. 2-4; Viveiros de Castro 2007, 159). As such, an argument could be made that the vessels are the material embodiment of myth manifested through the establishment of a figurative art tradition, three-dimensional beliefs given greater force by their material permanence. However, analogical reasoning, while important for laying out the possibilities of different worlds, does not necessarily actualize the ontological potential of those worlds. The logic of the myths themselves, if treated as 'the discourse of the Given' (Wagner 1978, as cited in Viveiros de Castro 2008) rather than stories, also reveals the unlikelihood of the pots representing mythic events. If identity conceived as 'disorganized bodies' (Viveiros de Castro 2007, 158) is an ongoing state, a truth established by myth itself, then to suggest that the pot 'represents' this 'story' is to remove the pot from that world. To follow the logic of the theory in its own terms would necessarily entail understanding the pot as part of the same 'ongoing' process of identity and world formation. It is quite probable that the figurative material played an active role in ritual (e.g. DeMarrias 2007, 255; Llamazares \& Sarasola 2006, 64-5) and that a connection exists between present-day Amazonian cosmologies and the archaeological material. A representationalist approach assumes that the thing as sign vehicle reveals a story or set of cultural beliefs inscribed in it and read off it. But, as demonstrated, a simple representationalist logic is actually counter to the terms of 'perspectivist' theory itself. To adopt such an approach to understanding the material - 'reading off' myth or worldviews - merely unreflexively imposes a separation between 'thing' and 'meaning'. This is not to say that forms of representation did not exist, but they would not necessarily be of the kind that we would immediately recognize (see Viveiros de Castro 2007 for an alternative Amazonian logic of representation). Thus, assuming a straightforward representationalist approach to the meaning of the pots undermines the possibilities of discovering the ontological logic they embody.

A different procedure is required for archaeology to reveal anomalies as such, one which is literalist (i.e. non-representationalist) and suspicious of potentially 'neutralizing' universal concepts, such as 'body' or 'gender' (Viveiros de Castro 2003). For example, the La Candelaria pots viewed conventionally are 'things' (pots) with a specific form and decorative aspect which is understood as the imprint of culture, i.e. as a representation of a body. In contrast to Holbraad's (2007) powder-power analysis, the confounding thing-concept is already fully entailed in the initial encounter. A twofold anomaly, this is in fact a 'potbody', where neither 'thing' (pot) nor 'concept' (body, as representation) matches exactly what we expect. An array of ontological possibilities are opened up, our access to which will be guided by the 'anomolies' of the material (once released from the thing/concept dualism) and the theory we bring to bear. General possibilities include a notion that all body-pots are ontologically equivalent; that the matter of flesh and the matter of ceramic pot 'bear' material truths in the same way (tattoos and engraved marks on pots are not distinct; or to break a pot and to break a body has the same material consequences). All of which is not to say that local representational regimes did not exist or are not, potentially, relevant to the understanding of 'body-pot'. However, the logic of 'representation' 
cannot be assumed and should be explored in each case (e.g. Viveiros de Castro 2007). Nonetheless, the relationship between body and pot is likely more than metaphorical. For example, when indications of sex on body-pots are found among the corpus (e.g. Fig. 4) the conventional question is one of seeing through the quirks of the local representational idiom of gender to the biological body that is presumed to be its referent. Within Western taxonomic schemes the presence or absence of certain sexed characteristics are used to place the figure into one of two categories on the basis of their culturally specific 'representation' of sex (e.g. Scattolin 2006; see Alberti 2006). Figure 4 is one of several vaguely similar forms. The shallow groove impressed in the clay between the 'legs' along with the presence of 'nipples' conventionally are taken to indicate sex, enabling the figure to be categorized as a representation of a female. The consequence, of course, is that any specifics (i.e. potential anomalies) are lost within the general analytic frame of sex/gender and binary sex. In contrast, on the basis of the material itself we could produce a new, locally conceived theoretical framework that built from such apparent anomalies. It is not necessarily the case that we have represented here a 'belief' that bodies were considered pot-like or pots were considered body-like, a simple metaphorical relationship; rather, the concept 'body-

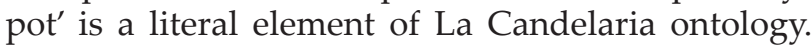
Once we treat the material as it is presented to us, the question What cultural variations of a given body are revealed? gives way to What is a body, what is a pot? or even What is gender, what is sex? In other words, what are the theoretical possibilities of this specific body-pot?

To animate these pots means thinking through them in terms of appropriate theories that are likely to reveal their alterity as ontological rather than epistemological. Examining the pots in light of the specific theoretical postulates of Barad, Ingold and perspectivism, two inter-related possibilities emerge: that matter and physical form were considered inherently unstable, and that the pots can be understood as inserting a difference and therefore bringing into local determinacy a potential belonging to indeterminate (or indifferent) but dynamic background matter.

Working with the concept of the 'chronically unstable body' elaborated on the basis of the theories of the northwest Amazon group, the Wari', by Aparecida Vilaça (2005; see Conklin 2001), Alberti (2007) argued that the La Candelaria and San Francisco pots and skeletal material indicated a concern with 'shoring up' the body, preventing its transformation into another body with another point of view. Combining

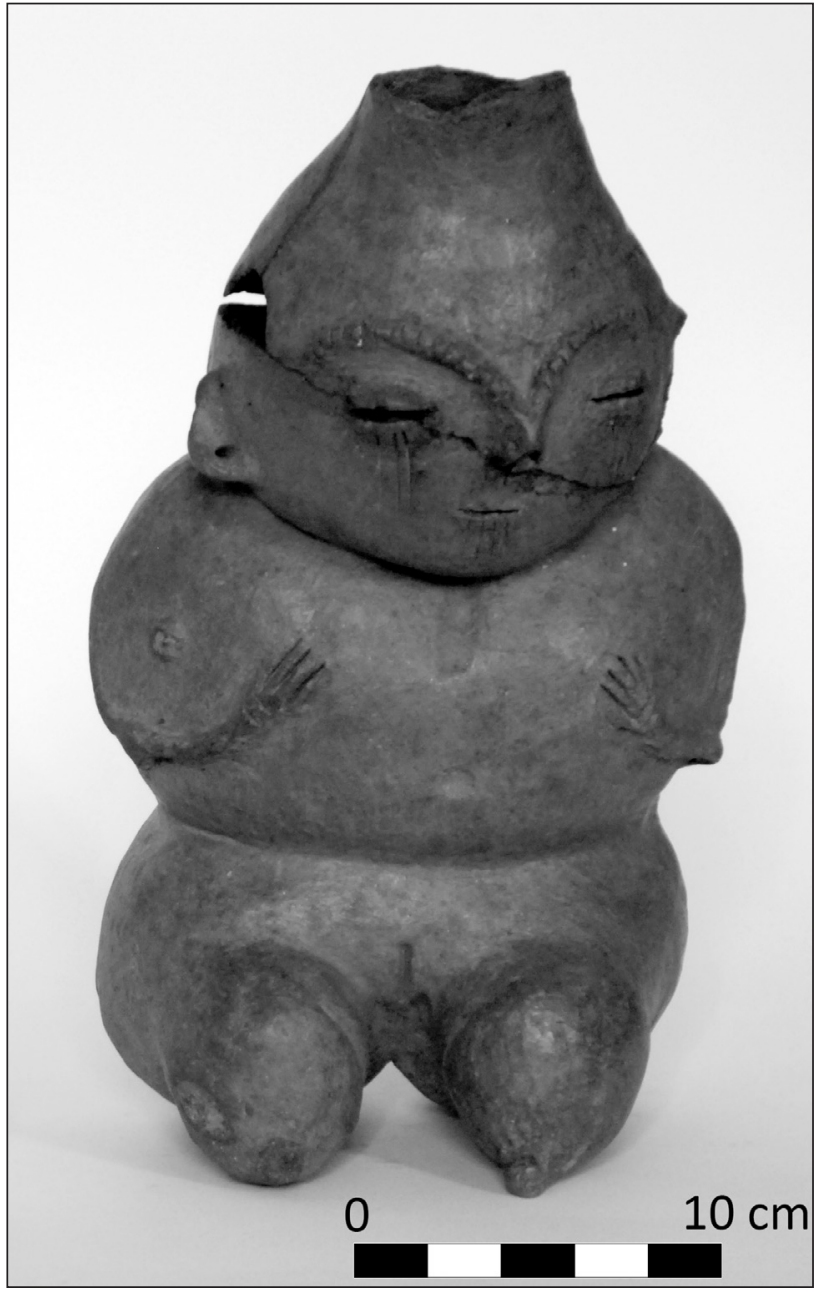

Figure 4. La Candelaria-style anthropomorphic bodypot. (Museo de la Universidad Nacional de Tucumán; photograph, B. Alberti.)

the perspectivist theory of the corporeal seat of identity with Ingold's (2007a) argument that 'materials' are flows, and properties 'histories', and Barad's (2007) insistence that matter is inherently indeterminate, one can argue that the volumes and forms of the ceramics do not so much 'represent' anything as 'participate in' an everyday concern with the instability of matter. Ingold's (2007a) challenge to the common-sense durability of matter, and his critique of notions such as 'materiality' which lead to essentialism (i.e. stone is hard because of its 'stoniness'), stretches the concept of matter as usually deployed in archaeology. The logic of the body-pot (i.e. as an extension of the concept body over pot, and likewise of the concept pot - as materials, not finished object - over body) reveals matter itself as conceptualized as unstable. This, then, was its 'natural' condition. 
With that general idea in mind, one way to understand specific differences in this material is to think of the body-pots as revealing notions about relatedness as 'inserting a difference' into a background of indifference. As such, the body-pot is not an agglomeration of attributes, body parts, sex marks, clay, water etc. that are added on successively to a fixed background of matter (i.e. the natural world, in a modern sense). Barad's (2007; see above) notion of 'phenomenon' captures a way to formalize the relationship in which a local resolution of generalized indeterminacy occurs and specific objects are crystallized out in determinate ways. Rather than bodies, sex, pots, and matter being thought of in an additive sense, their forms could be seen as a consequence of differentiating out - making determinate - certain characteristics, such as sex, from a generalized background of indifference. Those characteristics materialize as the difference that is inserted in order to establish a relation. That difference does not 'signify' sex, or even create a relation of 'identity' between that pot and a real woman. To think in terms of instability and in terms of an indifferent background suggests that the difference 'sex' makes here is at the literal level of matter. The sexed difference is marking and stabilizing that specific pot as sexed.

Matter and materials are actively involved in their own reconfiguration and in setting the terms of their own intelligibility (Barad 2007; Ingold 2007a). The existence of a strong correspondence between matter, practice and meaning in Barad's work (2007), indicates that 'matter' can be seen as inseparable from the actions it engenders. As such, separate worlds of, on the one hand, obdurate matter, and on the other, active practices do not exist. Rather, all processes and actions are 'natural' ones. Hence, to work on a body, a body-pot, or matter, is to ensure their stability as part of their natural processes, not as a cultural action 'layered over' stable, inert matter. Among the Wari', the affects that keep a body and therefore a point of view stable are such 'natural practices' as they are not considered cultural over and against a natural body (Conklin 2001; Vilaça 2005). In the same way, we argue, the on-going 'mattering' of the world can be conceived analogically as on-going 'affect'; matter too has to behave appropriately and to maintain its point of view or intelligibility (Barad 2007). In the case of the pots this parallelism between bodies and matter can be seen in the way body-pots are treated. Body-pots were worked on in an indistinguishable process to bodies, arguably to prevent their transformation and keep their points of view and bodies from transforming (Alberti 2007). The specific marks made on the body-pot in Figure 4, such as the impressed 'genitals', are affect-driven (i.e. practice-based), aimed to provide stability. For example, if 'times were hard', as has been argued through osteological analyses of the La Candelaria culture associated population at Las Pirguas caves (Baldini et al. 2003), it could be argued that matter was being experienced as increasingly unstable and therefore that appropriate affect was difficult to achieve, transformation increasingly immanent. Therefore, pots were mended, urn burials were re-opened, bodies were increasingly rearticulated, burned, or buried in novel ways (Baldini et al. 2003). The processes in which such material transformations were involved (whether 'natural' or 'cultural'), such as the stages of making, using, and eventually depositing a body-pot, were all aimed at bringing something into being from a generalized background of unindividuated matter and then preventing inappropriate transformation. However, matter was never 'fixed' even if it felt like it was (fired ceramic is harder than raw clay); fragility was about appropriate practice (affect), not some inherent quality of the 'substance' that we understand that material to be or become. The body-pot in its alterity reveals itself as the possible embodiment of the principle that matter is by its very nature affect dependent. The body-pot, therefore, embodies the antinomy of stability and instability, the instability of matter and the stabilizing effect of practice, whether human-authored or not. Consequently, the question of agency is reversed: the issue is no longer how things get movement (i.e. agency) but rather how they stabilize.

\section{Conclusion: chronically unstable theories}

The language of ontology is important precisely because it counteracts the tendency to see indigenous thought as fantasy, which happens when the 'natives' point of view' is reduced to a metaphor or worldview (Viveiros de Castro 2003, 14). The analogical use of animism in archaeology can shed light on an incredible array of cultural practices and beliefs, but it cannot reveal the past as any more different than the terms of the analogy dictate. In contrast, the theoretical and methodological starting point adopted here enables us to feel the actual (rather than derived) impact of animist theories on our interpretations. Our argument is that to get at ontological alterity through the past requires an approach that is open to the possibility of plural ontologies. 'Animist' theories of the world, such as perspectivism, present just such possibilities, as do contemporary theories of matter, such as those of Barad and Ingold. Importantly, we are not simply 
advocating 'theoretical eclecticism' - the outcome has to be a specific theory for a specific body of material because general frameworks limit our data's ability to 'extend our theoretical imagination' (Holbraad 2007, 190). The outcome of the specific analysis presented here, that matter was inherently unstable, is suggestive that perhaps our theories of matter need to be too. 'Source theories' that problematize ontology are likely to enable novelties to emerge from any archaeological material. There is no reason to assume that one theory is more or less appropriate than another from the outset. As such, the relevance of 'perspectivist' theory for archaeological explanation is not limited to explanations of 'perspectivists'. Archaeological ontologies ought to be singularities emergent from specific data and contexts rather than general frameworks applied to all cases, and the specific confluence of theories and materials (archaeological and otherwise) will enable non-predictable, materially different pasts to emerge.

Similarly, the categories of Western thought through which we operate are clearly obeying a specific ontological logic. Even so, they are not closed. Just as the gaps in dualist structures can be deliberate and themselves the object of thought (Viveiros de Castro 2006; see Alberti \& Bray, this issue), the engagement between Western categories and archaeological material is unscripted even if the terms of the debate are given. The traditional concepts of 'body' and 'pot' enable particular pasts to emerge and are archaeologically indispensable for all sorts of analyses. However, archaeological anomalies can also drive the reformulation of categories, whether the goal is to produce new concepts (Henare et al. 2007) or to 'stretch' our existing categories of thought (Viveiros de Castro 2006). Others are clearly struggling to enable alternative ontologies to break through the over-determination of dualist structures. For example, Marshall (2000) has shown how the tension in Wilson Duff's account of gender in a set of Northwest Coast stone objects resulted from his consistently dividing the material according to dualistic structures yet being sensitive to and searching for a way to articulate the complexity of the material.

The ontology of the past is present in the ways in which it is brought into determinate meaning by our writing about it. To say that 'both people and pots require work to prevent their transformation' is to suggest a commonality between people and pots where one is not expected. To incorporate that idea into future production is to change the terms of the use of the concepts in the discipline. This is not so much a 'proposition' about the past as an intervention, a work of conceptual elaboration in the present. It remains to be seen whether the potential ontological alterity - the 'para-ontologies' - implicit in our material can be made to reveal new worlds.

\section{Acknowledgements}

Our gratitude to Alejandra Korstanje and Eduardo Ribotta of the Museo de la Universidad Nacional de Tucuman, Argentina, for assistance researching material in their collections and for permission to reproduce photographs. BA is grateful to Chris Fowler and Jo Brück for the invitation to chair a session as part of their theme, 'Materializing Identities', at WAC-6, Dublin 2008. The present article has its roots in the paper delivered to the conference. Thank you to Tamara Bray, co-organizer and co-editor of this issue, and all the participants in the session for stimulating discourse around the topic of 'animating archaeology'. John Robb and an anonymous reviewer provided important constructive criticism, from which the article benefited, although we were unable to fully address their concerns here. We are grateful to Carl Martin, who provided invaluable editorial advice; and to Framingham State College philosophers Joe D'Andrea, Paul Bruno, and Doug Seale, who put up with incessant questions about ontology. Thank you to Karen Alberti, without whom this article could not have been written.

Ben Alberti

Department of Sociology

Framingham State College

100 State St

Framingham, MA 01701

USA

Email: balberti@framingham.edu

Yvonne Marshall

Department of Archaeology

University of Southampton

Avenue Campus

Highfield

Southampton

SO17 1BF

$U K$

Email:ymm@soton.ac.uk

\section{References}

Alberti, B., 2006. La diferencia sexual y objetos activos: cuerpos, sexo/género y cultura material, in Género y Etnicidad en la Arqueología Suramericana: Actas de la Segunda Reunión Internacional de Teoría Arqueológica en América del Sur, eds. V. Williams \& B. Alberti. Tandil: Ediciones INCUAPA, 73-85.

Alberti, B., 2007. Destabilizing meaning in anthropomorphic vessels from northwest Argentina. Journal of Iberian Archaeology 9/10, 209-30.

Baldini, M., E. Baffi, M. Salaberry \& M. Torres, 2003. Cande- 
laria: una aproximación desde un conjunto de sitios localizados entre los ceros de Las Pirguas y el Alto del Rodeo (Dto. Guachipas, Salta, Argentina), in La mitad Verde del Mundo Andino: Investigaciones Arqueológicas en la Vertiente Oriental de los Andes y las Tierras Bajas de Bolivia y Argentina, eds. G. Ortiz \& B. Ventura. Jujuy: Universidad Nacional de Jujuy, 131-51.

Barad, K., 2003. Posthumanist performativity: how matter comes to matter. Signs: Journal of Women in Culture and Society 28(3), 801-31.

Barad, K., 2007. Meeting the Universe Halfway: Quantum Physics and the Entanglement of Matter and Meaning. Durham (NC): Duke University Press.

Brown, L.A. \& K.F. Emery, 2008. Negotiations with the animate forest: hunting shrines in the Guatemalan Highlands. Journal of Archaeological Method and Theory 15(4), 300-37.

Brown, L.A. \& W.H. Walker, 2008. Prologue: archaeology, animism and non-human agents. Journal of Archaeological Method and Theory 15(4), 297-9.

Conklin, B., 2001. Consuming Grief: Compassionate Cannibalism in an Amazonian Society. Austin (TX): University of Texas Press.

Conneller, C., 2004. Becoming deer: corporeal transformations at Star Carr. Archaeological Dialogues 11(1), $37-56$.

DeMarrais, E., 2007. Early figuration in northwest Argentina: materiality, iconography, and the uses of imagery, in Image and Imagination: a Global Prehistory of Figurative Representation, eds. C. Renfrew \& I. Morley. (McDonald Institute Monographs.) Cambridge: McDonald Institute for Archaeological Research, 255-70.

Descola, P., 1996. Constructing natures: symbolic ecology and social practice, in Nature and Society: Anthropological Perspectives, eds. P. Descola \& G. Pálsson. London: Routledge, 82-102.

Descola, P., 2005. Par-Delà Nature et Culture. Paris: Editions Gallimard.

Dobres, M.-A. \& J.E. Robb, 2005. 'Doing' agency: introductory remarks on methodology. Journal of Archaeological Method and Theory 12(3), 159-66.

Fowler, C., 2004. The Archaeology of Personhood. London: Routledge.

Gardner, A., 2008. Agency, in Handbook of Archaeological Theories, eds. H.D.G. Bentley, C. Maschner \& R.A. Chippindale. Lanham (MD): Altamira, 95-108.

Gell, A., 1998. Art and Agency: an Anthropological Theory. Oxford: Oxford University Press.

González, A.R., 1977. Arte Precolombino de la Argentina. Buenos Aires: Filmediciones Valero.

Goretti, M. (ed.), 2006. Tesoros Precolombinos del Noroeste Argentino. Buenos Aires: Fundación CEPPA Ediciones.

Henare, A., M. Holbraad \& S. Wastell, 2007. Introduction: thinking through things, in Thinking Through Things: Theorising Artefacts Ethnographically, eds. A. Henare, M. Holbraad \& S. Wastell. London: Routledge, 1-31.

Heredia, O., 1968. Arqueologia de la subarea de las selvas occidentales. Actas y Memorias del XXXVII Congreso
Internacional de Americanistas 2, 295-353.

Heredia, O., 1975. Investigaciones arqueológicas en el sector meridional de las selvas occidentales. Revista del Instituto de Antropología, Universidad Nacional de Córdoba 5, 73-118.

Hodder, I., 1986. Reading the Past: Current Approaches to Interpretation in Archaeology. Cambridge: Cambridge University Press.

Holbraad, M., 2007. The power of powder: multiplicity and motion in the divinatory cosmology of Cuban Ifá (or mana, again), in Thinking Through Things: Theorising Artefacts Ethnographically, eds. A. Henare, M. Holbraad \& S. Wastell. London: Routledge, 189-225.

Ingold, T., 2000. The Perception of the Environment: Essays in Livelihood, Dwelling and Skill. London: Routledge.

Ingold, T., 2006. Rethinking the animate, re-animating thought. Ethnos 71(1), 9-20.

Ingold, T., 2007a. Material against materiality. Archaeological Dialogues 14(1), 1-16.

Ingold, T., 2007b. Writing texts, reading materials. A response to my critics. Archaeological Dialogues 14(1), 31-8.

Joyce, R. \& J. Lopiparo, 2005. Postscript: doing agency in archaeology. Journal of Archaeological Method and Theory 12(4), 365-74.

Knappett, C. \& L. Malafouris, (eds.) 2008. Material Agency: Towards a Non-Anthropocentric Approach. New York (NY): Springer.

Latour, B., 1993. We Have Never Been Modern. Cambridge (MA): Harvard University Press.

Lazzari, M., 2005. The texture of things: objects, people, and landscape in northwest Argentina (first millenium AD), in Archaeologies of Materiality, ed. L. Meskell. Malden (MA): Blackwell, 126-61.

Lévi-Strauss, C., 1969. The Raw and the Cooked: Mythologiques, vol. 1. Chicago (IL): University of Chicago Press.

Llamazares, A.M. \& C.M. Sarasola, 2006. Reflejos de la cosmovisión originaria: arte indígena y chamanismo en el Noroeste argentina prehispánico, in Tesoros Precolombinos del Noroeste Argentino, ed. M. Goretti. Buenos Aires: Fundación CEPPA Ediciones, 63-92.

Marshall, Y.M., 2000. Reading images stone вс. World Archaeology 32(2), 222-35.

Marshall, Y., 2008. Archaeological possibilities for feminist theories of transition and transformation. Feminist Theory 9(1), 25-45.

Olsen, B., 2003. Material culture after text: re-membering things. Norwegian Archaeological Review 36(2), 87-104.

Parker Pearson, M., J. Pollard, C. Richards, et al., 2006. Materializing Stonehenge. Journal of Material Culture 11(1-2), 227-61.

Pérez Gollán, J.A., 2000. El jaguar en llamas. La religión en el antiguo noroeste argentino, in Nueva Historia Argentina: Los Pueblos Originarios y la Conquista, ed. M.N. Tarragó. Barcelona: Sudamericana, 229-56.

Robb, J.E., 2005. The extended artefact and the monumental economy: a methodology for material agency, in Rethinking Materiality: the Engagement of Mind with the Material World, eds. E. DeMarrais, C. Gosden 
\& C. Renfrew. (McDonald Institute Monographs.) Cambridge: McDonald Institute for Archaeological Research, 131-9.

Robb, J.E., 2008. Tradition and agency: human body representations in later prehistoric Europe. World Archaeology 40(3), 332-53.

Rollason, W., 2008. Ontology - just another word for culture? Anthropology Today 24(3), 28-9.

Scattolin, M.C., 2006. La mujer que carga el cántaro, in Género y Etnicidad en la Arqueología Suramericana: Actas de la Segunda Reunión Internacional de Teoría Arqueológica en América del Sur, eds. V. Williams \& B. Alberti. Tandil: Ediciones INCUAPA, 43-72.

Sillar, B., 2004. Acts of god and active material culture: agency and commitment in the Andes, in Agency Uncovered, ed. A. Gardner. London: UCL Press, 153-209.

Strathern, M., 1988. The Gender of the Gift: Problems with Women and Problems with Society in Melanesia. Berkeley (CA): University of California Press.

Thomas, J., 2004. Archaeology and Modernity. London: Routledge.

Tylor, E.B., 1993 (1871). Primitive Culture: Researches into the Development of Mythology, Philosophy, Religion, Art, and Custom. London: J. Murray.

Vilaça, A., 2005. Chronically unstable bodies: reflections on Amazonian corporalities. Journal of the Royal Anthropological Institute 11(3), 445-64.

Viveiros de Castro, E., 1998. Cosmological deixis and Amerindian perspectivism. The Journal of the Royal Anthropological Institute 4(3), 469-88.

Viveiros de Castro, E., 2002. O nativo relativo. Mana 8(1), $113-48$.

Viveiros de Castro, E., 2003. Anthropology (AND) science. http://abaete.wikia.com/wiki/. (Also published in Manchester Papers in Social Anthropology, 7.)

Viveiros de Castro, E., 2004a. Perspectival anthropology and the method of controlled equivocation. Tipiti 2(1), 3-22.

Viveiros de Castro, E., 2004b. Exchanging perspectives: the transformation of objects into subjects in Amerindian ontologies. Common Knowledge 10(3), 463-84.

Viveiros de Castro, E., 2006. A Inconstância da Alma Selvagem. 2nd edition. São Paulo: COSAC NAIFY.

Viveiros de Castro, E., 2007. The crystal forest: notes on the ontology of Amazonian spirits. Inner Asia 9, 153-72.

Viveiros de Castro, E., 2008. Intensive filiation and demonic alliance. http://abaete.wikia.com/wiki/. (Forthcoming in Deleuzian Intersections in Science, Technology and Anthropology, eds. C.B. Jensen \& K. Rödje. Oxford: Berghahn Books).

Weismantel, M., 2004. Moche sex pots: reproduction and temporality in ancient South America. American Anthropologist 106(3), 495-505.

Witmore, C.L., 2007. Symmetrical archaeology: excerpts of a manifesto. World Archaeology 39(4), 546-62.

\section{Author biographies}

Benjamin Alberti is Associate Professor of Anthropology at Framingham State College, and also lectures at the Universidad Nacional de Córdoba, Argentina. He has published on sex/gender, masculinity and anthropomorphism in both South American archaeology and Bronze Age Crete. Currently, he is researching anthropomorphism and notions of materiality in northwest Argentina.

Yvonne Marshall is a Senior Lecturer at the University of Southampton. She has conducted archaeological research in New Zealand, Fiji, British Columbia Canada and is now starting a new research project on Paiwan archaeology, southern Taiwain with colleagues at National Taiwan University. Her wider interests encompass the archaeology of the Pacific Rim Region generally. She also has a longstanding interest in the application of feminist theory to archaeology and is currently exploring the archaeological heritage of the Greenham Common Women's Peace Camps in Berkshire, England, and writing abook on feminist theory and archaeology. 